\title{
Rupture uterus: a prospective observational study of 25 consecutive cases in a tertiary referral centre in South India
}

\author{
Rashmi Desai*, Amitha V. Kamat \\ Department of Obstetrics and Gynecology, Karnataka Institute of Medical Sciences, Hubballi, Karnataka, India
}

Received: 05 April 2017

Accepted: 02 May 2017

*Correspondence:

Dr. Rashmi Desai,

E-mail: drrashmi.mankani@gmail.com

Copyright: () the author(s), publisher and licensee Medip Academy. This is an open-access article distributed under the terms of the Creative Commons Attribution Non-Commercial License, which permits unrestricted non-commercial use, distribution, and reproduction in any medium, provided the original work is properly cited.

\begin{abstract}
Background: Uterine rupture in pregnancy is a rare though catastrophic complication with a high incidence of foetal and maternal morbidity. It appeared to be on the decline in recent times, prompting us to analyse the clinical picture now. The objective of the study was to study the risk factors, clinical profile and consequences of uterine rupture on maternal and perinatal outcome.

Methods: A prospective observational study of 25 consecutive cases of uterine rupture was carried out between July 2013 and October 2015. All the cases of rupture uterus either referred or diagnosed after admission were included. Detailed demographic data, past and present obstetric events, time taken to reach the referral centre, the reasons for any delay, mode of presentation, type of rupture, management and maternal and foetal outcomes were analysed.

Results: The incidence of rupture was 1 in 915 deliveries. Seventy-two per cent of them were referred cases. Average time to reach from referral centre was 4.3 hours, the common reasons for delay being patient factors (33\%), transport problems $(38 \%)$ and delayed referrals $(22 \%)$. Previous caesarean section was the most common predisposing factor $(56 \%)$. Sixty-four per cent of the ruptures were diagnosed clinically. Eighty-four per cent of the ruptures were complete. Sub-total hysterectomy was carried out in 14 (56\%) patients. Internal iliac artery ligation (20\%) and bladder repair $(8 \%)$ were sometimes required. All women required blood transfusion. Perinatal mortality was seen in $76 \%$. There was no maternal mortality.

Conclusions: Uterine rupture is a cause of severe acute maternal morbidity and very high perinatal mortality. Delay in referral and diagnosis can lead to significant maternal morbidity and hysterectomy.
\end{abstract}

Keywords: Maternal mortality, Morbidity, Rupture uterus, Scar uterus

\section{INTRODUCTION}

Uterine rupture in pregnancy is a rare and often catastrophic complication with a high incidence of foetal morbidity and mortality and an occasional cause of severe acute maternal morbidity or mortality. ${ }^{1}$ It appeared to be on the decline over the last decade, prompting us to analyse the morbidity and mortality associated with it and study the clinical picture of rupture uterus in our hospital. Rupture uterus is defined as a full-thickness disruption of the uterine wall that also involves the overlying visceral peritoneum. ${ }^{1}$ It may be primary, defined as occurring in a previously intact or unscarred uterus, or may be secondary and associated with a pre-existing myometrial incision, injury, or anomaly. ${ }^{2}$ It may be complete or incomplete (also referred as uterine dehiscence) depending on whether the visceral peritoneum is breached or is intact, respectively. ${ }^{2}$ Incidence of rupture uterus though varies widely from 1:110 in developing countries like Ethiopia to as less as 1:4366 in developed countries. ${ }^{3,4}$ In India the reported incidence varies from 1 in 1633 deliveries to 1 in 346 deliveries. ${ }^{5-8}$ Uterine 
rupture in developing countries in the past mostly used to be due to obstructed labour more so in multigravida. ${ }^{9,10}$ But now with increasing rates of caesarean sections $(5 \%$ in 1970 to $26 \%$ in 2003), scar ruptures are more common. ${ }^{11}$ Other causes are prostaglandin use, injudicious use of oxytocin, traumatic causes like internal podalic version, manual removal of placenta and instrumental deliveries. Diagnosis of rupture uterus is an enigma as there are no specific or universal clinical features. Patient's history and examination are very important. In high risk patients, continuous cardiotocograph monitoring during labour wherever available is very useful to detect rupture at the earliest as abnormal fetal heart rate pattern is the first sign. ${ }^{12}$ Ultrasound abdomen can be useful to demonstrate breach in uterine layers, to detect hemoperitoneum and extrusion of foetus and placenta outside the uterine cavity. A very high perinatal mortality is the hallmark of rupture uterus, the incidence ranging from $75 \%$ to $93 \% .^{13,14}$ Presently maternal mortality due to rupture uterus ranges from 0 $1 \%$ in developed countries and $5-10 \%$ in developing countries. $^{1,6}$ This study was done to evaluate the risk factors, clinical profile and consequences of uterine rupture on maternal and perinatal outcomes in our hospital.

\section{METHODS}

A prospective observational study of 25 consecutive cases of uterine rupture was carried out between July 2013 to October 2015, in the Department of Obstetrics and Gynaecology, Karnataka Institute of Medical Sciences (KIMS), Hubballi, Karnataka state, India. This is a government medical college and serves as a tertiary care hospital and a major referral centre for both urban and rural areas of the northern part of Karnataka state, covering about 7-8 districts. All the cases of rupture uterus diagnosed clinically, by ultrasound or during surgery, either referred from primary care centres with this complication or developed in KIMS were included in the study. Detailed history was taken regarding demographic data, past obstetric events like previous surgeries on the uterus like caesarean section, myomectomy, dilatation and curettage, previous rupture uterus and details of events preceding the rupture. In the present pregnancy predisposing factors for rupture uterus such as prolonged or obstructed labour, induction and augmentation of labour and use of prostaglandins were noted. Coexisting medical conditions like anaemia, preeclampsia, diabetes mellitus, renal or liver disorders were also noted. Data regarding antenatal care, details of referral - whether referred from primary care centre with or without the diagnosis being made, or whether developed the rupture in KIMS, time taken to reach KIMS and the reason for any delay were noted. Mode of clinical presentation, type of rupture, the management, maternal and foetal outcome were analysed in detail. Management included either primary repair of uterus or its conservation with or without tubal ligation or hysterectomy depending upon the condition of the patient at the time of presentation, type, severity and extent of rupture and future desirability of fertility. Maternal complications, blood loss, transfusion requirements were analysed. Data was analysed using SPSS version 20.0.

\section{RESULTS}

There were 25 cases of rupture of the pregnant uterus in the period between July 2013 and October 2015. There were total of 22,876 deliveries in the same period of time. That makes the incidence of uterine rupture as $0.11 \%$ or 1 in 915 deliveries in our study. The median age of the women was 25 (22-30) years. Most of the women were gravida $2(52 \%)$ or $3(40 \%$ ) (Table 1$)$. We did not see any grand-multipara in our study.

Table 1: Antenatal patient profile.

\begin{tabular}{|lll|}
\hline Parameter & Number $(\mathbf{n = 2 5})$ & $\%$ \\
\hline Gravida 1 & 2 & 8 \\
\hline Gravida 2 & 13 & 52 \\
\hline Gravida 3 & 10 & 40 \\
\hline Duration of gestation & & \\
\hline Pre-term & 0 & 0 \\
\hline Full term & 21 & 84 \\
\hline Post term & 4 & 16 \\
\hline Antenatal care & & \\
\hline Booked & 5 & 20 \\
\hline Un booked & 2 & 8 \\
\hline Referred & 18 & 72 \\
\hline
\end{tabular}

Five women had antenatal follow up in our hospital. Eighteen $(72 \%)$ of the 25 women were referred from primary health centres or other taluka or district hospitals (hence forward referred to collectively as primary care centres). Only 3 of the 18 women (16\%) referred from other centres were diagnosed as uterine rupture in the primary care centre, whereas the rest of them (15 of 18 women, $83 \%$ ) were referred as either prolonged/obstructed labour or anticipating some other complication. Two (8\%) women had not received any antenatal care and came directly to our hospital with rupture uterus.

From the time of referral, time taken to reach KIMS was $4.3 \pm 4.4$ hours. In most of the cases, the delay was attributed to the patient taking time after the referral advice (6 women), non-availability of transport facility ( 7 women) or remote location of primary centre needing longer time to reach the tertiary care hospital or delayed referrals (4 women).

The common presenting symptoms were acute pain, absence of foetal movements, prolonged labour, and bleeding per vaginum.

Rupture of a scarred uterus was the most common (56\%) event. Only two of the women with previous caesarean had one vaginal birth following caesarean section 
(VBAC) each. All the other women had uterine rupture in the pregnancy immediately following the previous caesarean. Prolonged or obstructed labour was the cause of rupture of uterus in $32 \%$ of women. Prostaglandin use for induction of labour was associated in $8 \%$ of the women (all in unscarred uterus), and Oxytocin augmentation was seen in $4 \%$ (Figure 1).

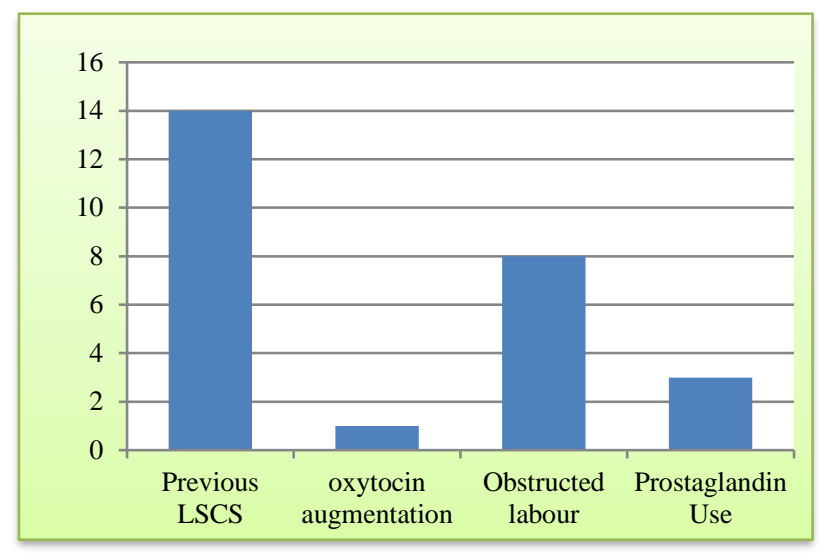

Figure 1: Predisposing Factors for uterine rupture.

Most of the ruptures were diagnosed clinically. Ultrasound and cardio-tocograph was the modality used to diagnose rupture in one woman each. In seven women, uterine rupture was diagnosed intra-operatively.

Twenty-one $(84 \%)$ of the 25 ruptures were complete and four were incomplete. Almost half of the uterine ruptures were transverse and it was longitudinal in 7 and irregular in 6 patients. Scar and anterior wall were the most common sites of rupture $(52 \%)$ followed by lateral wall and posterior wall (Table 2).

Table 2: Site and direction of uterine rupture.

\begin{tabular}{|c|c|c|}
\hline Parameter & Number $(\mathrm{n}=\mathbf{2 5})$ & $\%$ \\
\hline Incomplete & 4 & 12 \\
\hline Complete & 21 & 88 \\
\hline \multicolumn{3}{|c|}{ Direction of Tear } \\
\hline Transverse & 12 & 48 \\
\hline Longitudinal & 7 & 28 \\
\hline Irregular & 6 & 24 \\
\hline \multicolumn{3}{|c|}{ Site of rupture (more than one in some cases) } \\
\hline Scar & 11 & \\
\hline Anterior wall & 5 & \\
\hline Lateral wall & 4 & \\
\hline Posterior wall & 6 & \\
\hline
\end{tabular}

Sub-total hysterectomy was carried out in 14 (56\%) patients and primary repair was done with or without tubectomy in $11(44 \%)$ women. Five $(20 \%)$ women needed internal iliac artery ligation for post-partum haemorrhage (1 case) or pelvic haemostasis post hysterectomy (4 cases). Eleven (44\%) women required admission to the Intensive care unit. Mean haemoglobin level on admission was $8.1( \pm 1.4)$ gm\%. Mean blood loss was $1209( \pm 244) \mathrm{ml}$ and all women required blood transfusion (mean $2.3 \pm 0.8$ units).

Complications (Table 3) noted in the postoperative period were paralytic ileus $(40 \%)$, acute renal failure (16\%), febrile morbidity (20\%), Disseminated intravascular coagulopathy $(8 \%)$, deep vein thrombosis (4\%), vesico-vaginal fistula (4\%), acute lung injury $(4 \%)$ and burst abdomen (4\%). Twelve $(48 \%)$ of the women had one or the other complication, with few having multisystem involvement (Table 3 ).

Table 3: Maternal and perinatal complications.

\begin{tabular}{|lll|}
\hline Maternal Complications & Number $(\mathbf{n = 2 5})$ & $\%$ \\
\hline Paralytic ileus & 10 & 40 \\
\hline Acute renal failure & 4 & 16 \\
\hline Febrile morbidity & 5 & 20 \\
$\begin{array}{l}\text { Disseminated intravascular } \\
\text { coagulation }\end{array}$ & 2 & 8 \\
Deep vein thrombosis & 1 & 4 \\
\hline Vesico-vaginal fistula & 1 & 4 \\
\hline Acute lung injury & 1 & 4 \\
\hline Burst abdomen & 1 & 4 \\
\hline Maternal mortality & 0 & 0 \\
\hline Perinatal mortality/morbidity & \\
Mortality & 19 & 76 \\
\hline Neonatal sepsis & 4 & 16 \\
\hline $\begin{array}{l}\text { Hypoxic Ischemic } \\
\text { Encephalopathy }\end{array}$ & 2 & 8
\end{tabular}

The mean duration of stay in our hospital was $12.2( \pm 3.8)$ days. There was no maternal mortality in our study. The perinatal mortality was $76 \%$ (Table 3 ).

\section{DISCUSSION}

Our hospital is a tertiary care centre, which is a major referral centre for all small hospitals in the radius of 100$150 \mathrm{~km}$ and caters to both urban and rural population. In our study, the incidence of rupture uterus was $0.11 \%$, which was much less compared to the incidence reported from other developing countries; $0.8 \%$ in Ghana, $0.76 \%$ in Uganda, $0.74 \%$ in Pakistan, $0.9 \%$ in Nepal, $2.8 \%$ in Ethiopia and $0.63 \%$ in Yemen. ${ }^{15-20}$ Studies from developed countries showed incidences as low as $0.035 \% .^{21}$ The incidence in other Indian studies is comparable to our study varying from $0.061 \%$ to $0.28 \%$. 5 ${ }^{8}$ Majority of our subjects were in the age group of 22-30 years, mean age being 25 years. In a study by Sahu L in India $73.12 \%$ were in the age group of $20-30$ yrs. $^{7}$ In another study by Sunitha $\mathrm{K}$ et al majority were in age group of 26-30 yrs. ${ }^{6}$

Scarred uterus emerged as the most susceptible to rupture in our study. Second or third gravida with previous caesarean section were the most vulnerable group followed by multiparas with prolonged labour and the use of oxytocics for the induction or augmentation of labour. 
Two of the women were primigravidae with an unscarred uterus, the cause of rupture being obstructed labour in one and misoprostol induction in the other. This is also the pattern seen in other recent Indian studies. ${ }^{5,6,8}$ On the contrary Gupta A et al in 2011 reported a higher incidence of spontaneous ruptures than scar ruptures. ${ }^{7}$

We did not have any grand multiparas in present study, whereas this number is quite high in some other studies; $41.5 \%$ in the Ghana study, $65 \%$ in the Yemen study, $28.6 \%$ in an Indian study. ${ }^{14,19,5}$

All the cases were of either term $(84 \%)$ or post term (16\%) pregnancy. None of the patient with uterine rupture in our study was of preterm.

Out of 25 women, 18 (72\%) were referred to us, had antenatal follow up in other primary care centre, they were referred to our institution for complications and $5(20 \%)$ had antenatal follow up in our hospital and 2(8\%) were did not have any antenatal follow up anywhere. This reflects an aversion in some rural populations to the institutional delivery and they come to a hospital only after failure of efforts to vaginal delivery at home (usually attended by traditional birth attendants). Primary care centres from where patients were referred were Primary health centres, Community health centres and District hospitals. Out of 5 patients who were booked in our hospital, 2 patients were in labour for 6-7 hours with a previous caesarean, again with the intention to avoid a surgical delivery. Our hospital policy is to admit patients for safe confinement at 39 weeks if they had previous one caesarean section and at 37 weeks if they had previous two caesarean sections. Three other booked women were undergoing trial of labour after caesarean (TOLAC) in our labour room, who developed rupture uterus during the trial.

Spontaneous unscarred uterine rupture was noted in $28 \%$ of our subjects. In other studies, like in the Nigerian study and the Yemen study, the proportion of obstructed labours leading to ruptures was very high. ${ }^{19,20}$ Ruptures of the uterus related to injudicious use of oxytocics, Oxytocin or Prostaglandins, was noted in $12 \%$ of our subjects. The same was comparable to $18 \%$ quoted by Sunitha $\mathrm{K}$ et al, and $5.52 \%$ in the study done by Sahu L et al. ${ }^{6,8}$ In the study from Yemen these figures, pertaining to use of Oxytocin infusion are very high- $41.7 \% .^{20}$

Diagnosis was on the basis of clinical presentation in all except two of our cases; symptoms of pain abdomen, vaginal bleeding, prolonged labour; signs like poorly defined uterine contour, superficially felt foetal parts, absent foetal heart sounds, severe anaemia, sudden collapse or those presenting with shock, were most often corroborated by paracentesis to demonstrate haemoperitoneum. Cardiotocograph picked up the foetal bradycardia, in one case of TOLAC. In another woman with previous LSCS presenting with pain abdomen and loss of foetal movements was diagnosed as rupture uterus by ultrasonography. Revicky et al in a review of 12 cases of rupture uterus, concluded that prolonged, persistent and profound bradycardia as the most consistent early indicator of uterine rupture. ${ }^{12}$ But in developing countries late symptoms and signs are the ones that clinch the diagnosis. $^{15}$

In $84 \%$ of our subjects, the rupture of the uterus was complete. In other studies, complete rupture was noted in $66 \%$ by Sahu L, $57.1 \%$ by Dhaifalah I and $88 \%$ by Sunitha K. ${ }^{8,20,6}$ In $52 \%$, the tear involved the previous uterine scar or the anterior wall. This is expected considering that scar ruptures are the commonest aetiology seen. Lower uterine scar rupture was seen in $89.72 \%$ of rupture cases by Sahu L et al. ${ }^{8}$ Anterior wall was the most common site of rupture in in $84.4 \%$ of scarred uterus ruptures and $50 \%$ of unscarred uterus ruptures in the study done by $\mathrm{Al}$ Salem $\mathrm{MH}$ et al, in $57.4 \%$ in the study by Gessesse A et al and $60 \%$ of cases in the study by Rizwan $\mathrm{N}$ et al. . $2,3,17^{2}$

The most common mode of management in our institution was subtotal hysterectomy $(56 \%)$. Wherever possible the rent in the uterus was repaired. In a study done in Pakistan, Rizwan $\mathrm{N}$ reported a hysterectomy rate of $53.3 \%$, whereas hysterectomy was performed only in $20 \%$ of the cases in the study from Yemen. ${ }^{17,20}$ In other Indian studies also the hysterectomy rate varied; $41.5 \%$ in Pondicherry, 32\% in Andhra Pradesh, 29.82\% in Rohtak and only $17 \%$ from New Delhi. ${ }^{8,6,7,5}$ Other surgical procedures like Internal Iliac artery ligation was performed in 5 women in our study.

Intensive care unit in admission was needed in 11 women, which could possibly due to delay in reaching our institute and critical condition at time presentation. All 25 women required blood transfusion, which is not the case in most of the studies including those from African countries. ${ }^{5,8,15}$ The reason for such high rates of blood transfusion in our women could be that most of them start the pregnancy with anaemia. Haemoglobin at time of admission was less than or equal to $8 \mathrm{gm} \%$ in $56 \%$ of the women.

Complications that were seen in our patients are comparable to other studies on uterine rupture. These include bladder injury, shock, loss of fertility consequent to tubal ligation or hysterectomy, febrile morbidity, cervical laceration, wound infection, urinary tract infection, respiratory tract infection, paralytic ileus, pulmonary embolism, septicaemia, acute renal failure, vesico-vaginal fistula, disseminated intravascular coagulopathy, multi-organ failure. Maternal outcome depends upon the coexisting medical or obstetric conditions, type of rupture, time interval between rupture and treatment, operative procedure, associated complications, availability of blood and its components and other supportive measures. The perinatal mortality in our institute was $76 \%$. Previous studies have shown that prompt delivery of the infant has no effect on the 
outcome, unless rupture occurring in the same institute may help to salvage some babies. Yet the morbidity of surviving neonates also is very high. Morbidity is mainly in the form of severe metabolic acidosis and hypoxic ischemic encephalopathy, which may not be preventable even with the promptest intervention. ${ }^{14}$

A WHO systematic review of maternal morbidity and mortality showed that the prevalence of ruptured uterus ranged between $0.006 \%$ for women without previous caesarean section from a developed country and $25 \%$ for women with obstructed labour in a least developed country. ${ }^{23}$ Most studies show foetal mortality varying between 56.8 to $94.74 \%$ and maternal death in the range of 0 to $5.9 \% .^{7,13} \mathrm{We}$ had no maternal death in this series. The absence of maternal death may reflect the awareness among health workers in peripheral health centres and the relatively improved blood bank facilities, operation theatre conditions and intensive care facilities available in our institute today.

\section{CONCLUSION}

Rupture of the pregnant uterus causing severe acute maternal morbidity and high foetal mortalities constitutes a preventable entity. The results of our study prove that poor antenatal care, lack of awareness among the population about the complications that can occur in a labour with scarred uterus, poor infrastructure related to roads and transport, poor intra-partum monitoring facilities and manpower in the health sector are the main reasons for this condition.

All of which are either preventable or correctable. Every effort should be made to improve education regarding antepartum and intra-partum care among pregnant women and their families. TOLAC should be conducted under vigilant care in a well-equipped and adequately staffed facility.

Medical officers should be strictly involved in decisions to induce or augment labour. Partograms should be used in every labour and guideline based early referral should be encouraged from all primary health centres. Such concerted efforts can bring down the incidence of uterine rupture and its associated maternal mortality and morbidity.

Funding: No funding sources Conflict of interest: None declared

Ethical approval: Not required

\section{REFERENCES}

1. Nahum GG, Pham KQ. Uterine rupture in pregnancy; 2011. available from URL http://reference.medscape.com/article/275854.

2. Cunningham F. In Obstetrical Hemorrhage pp 79093 and Prior Caesarean Delivery, pp 609-20; Cunningham FG, Leveno KJ, Bloom SL, Spong CY et al (eds.), William's Obstetrics, $24^{\text {th }}$ edition, by McGraw-Hill Education; 2014.

3. Gessesse A, Melese MM. Ruptured uterus-eight year retrospective analysis of causes and management outcome in Adigrat Hospital, Tigray region, Ethiopia. Ethiop J Health Dev. 2002;16:241-5.

4. Gardiel FF, Daly SS, Turner MJ. Uterine rupture in pregnancy reviewed. Eur J Obstet Gynecol Reprod Biol.1994;56:107-10.

5. Sinha M, Gupta R, Gupta P, Rani R, Kaur R, Singh R. Uterine rupture: A seven year review at a tertiary care hospital in New Delhi, India. Indian $\mathbf{J}$ Community Med. 2016;41:45-9.

6. Sunitha K, Indira I, Suguna P. Clinical study of rupture uterus- Assessment of Maternal and fetal outcome. IOSR Journal of Dental and Medical sciences/ 2015;14:39-45.

7. Gupta A, Nanda S. Uterine rupture in pregnancy: a five year study. Archives of Gynaecology and Obstetrics. 2011;283:437-41.

8. Sahu L. A 10 year analysis of uterine rupture at a teaching institution. $\mathbf{J}$ Obstet Gynecol India. 2006;56:502-6

9. Oronsaye AU, Asuquo EE. Rupture of the uterus in a Nigerian Hospital. Singapore J. Obstet. Gynaecol. 1980;2:37-42.

10. Rotimi EO, Olamijulo JA. Rupture of the uterus at the Lagos University teaching hospital, Lagos, Nigeria. West Afr. Med. J. 1998.17:188-93.

11. Hamilton BE, Martin JA, Sutton PD. Births in preliminary data for 2002. Nat Vital Stat Rep. 2003;51:1-20.

12. Revicky V, Muralidhar A, Mukhyopadhyay S, Mahmood T. A case series of uterine rupture: lessons to be learned for future clinical practice. J Obstet Gynecol India. 2012;62:665-73.

13. Ehigiegba AE, Adeyemo IS. Uterine rupture in labour: a continuing obstetric challenge in developing countries- the Benin experience. J Med Biomed Research. 2006;5:44-50.

14. Bujold E, Gauthier RJ. Neonatal morbidity associated with uterine rupture: what are the risk factors? Am J Obstet Gynecol. 2002;186:311-4.

15. Fofie $\mathrm{CO}$, Baffoe $\mathrm{P}$. A two-year review of uterine rupture in a regional hospital. Ghana Med J. 2010; 44:98-102

16. Mukasa PK, Kabakyenga J, Senkungu JK, Ngonzi J, Kyalimpa M, Roosmalen VJ. Uterine rupture in a teaching hospital in Mbarara, Western Uganda, unmatched case-control study. Reprod Health. 2013; 10:29.

17. Rizwan N, Abbasi RM, Uddin SF. Uterine rupture, frequency of cases and feto-maternal outcome. J Pak Med. Assoc. 2011;61:322-4.

18. Padhye SM. Rupture of the pregnant uterus: A 20 year review. Kathmandu Univ. Med. J.2005; 3:234-8

19. Omole-Ohonsi and Attah. Uterine Rupture: risk factors and pregnancy outcome. Gynecol. Obstet. 2011;1:102. 
20. Dhaifalah I, Santavy J, Fingerova H. Uterine rupture during pregnancy and delivery among women attending the Al- Tthawra hospital in Sana'a city, Yemen Republic. Biomed Pap Med Fac Univ Palacky Olomouc Czech Repub. 2006:150:279-83.

21. Ofir K, Sheiner E, Levy A, Katz M, Mazor M. Uterine Rupture: differences between a scarred and an unscarred uterus. Am. J. Obstet. Gynecol. 2004; 19:425-9.

22. Al Salem MH, Makhseed M, Ahmed MA, Gupta M. rupture of the gravid uterus: Experience of the maternity Hospital, Kuwait. Med Principles Pract. 2000;9:97-105.
23. WHO systematic review of maternal mortality and morbidity: the prevalence of uterine rupture. BJOG. 2005;112:1221-28.

Cite this article as: Desai R, Kamat AV. Rupture uterus: a prospective observational study of 25 consecutive cases in a tertiary referral centre in south India. Int J Reprod Contracept Obstet Gynecol 2017;6:2601-6. 